\title{
TECNOLOGIAS DIGITAIS NO ENSINO E NA FORMAÇÃO DOCENTE SEGUNDO A VISÃO DE ESTUDANTES DE LICENCIATURA EM MATEMÁTICA
}

\author{
DIGITAL TECHNOLOGIES IN TEACHING AND TEACHER EDUCATION \\ ACCORDING TO THE VIEW OF MATHEMATICS UNDERGRADUATE STUDENTS
}

\author{
Rita de Cássia Idem \\ Mestre em Educação Matemática \\ Universidade Estadual Paulista - UNESP \\ Rio Claro, São Paulo - Brasil \\ idem.ritadecassia@gmail.com \\ Ricardo Scucuglia Rodrigues da Silva \\ Doutor em Education Studies \\ Universidade Estadual Paulista - UNESP \\ São José do Rio Preto, São Paulo - Brasil \\ ricardo.scucuglia@unesp.br
}

\begin{abstract}
Resumo: Este estudo qualitativo objetivou apresentar e discutir as visões de futuras docentes em relação à integração das tecnologias digitais no ensino de Matemática e na formação de professores. Participaram da pesquisa, quatro estudantes em níveis distintos do curso de Licenciatura em Matemática de uma universidade pública paulista. Os dados foram produzidos por meio de gravação em áudio no contexto de um curso de extensão universitária, que configura o cenário da pesquisa. Esse curso teve como público-alvo professores e futuros professores de Matemática e abordou as possibilidades do GeoGebra para o ensino e para a aprendizagem de Geometrias Plana e Espacial, além de promover discussões sobre a integração das tecnologias digitais no ensino. Este estudo que se apresenta foca em uma discussão ocorrida em um dos encontros do curso. Essa discussão foi considerada uma entrevista coletiva e foi analisada à luz de processos qualitativos. Os resultados, que são apresentados por meio de categorias e subcategorias, evidenciam que as estudantes consideram que as tecnologias digitais são importantes tanto no aprendizado de conteúdos matemáticos, como na formação dos futuros professores, mas avaliam que essa temática tem sido negligenciada em sua própria formação docente e no ensino de Matemática na Educação Básica.
\end{abstract}

Palavras-chave: Educação matemática. Formação inicial de professores. Tecnologias digitais.

\begin{abstract}
This qualitative study aimed to present and discuss the views of future teachers in relation to the integration of digital technologies in the teaching of Mathematics and in the teacher education. Four students participated in the research at different levels of the Mathematics course at a public university in São Paulo. The data were produced by audio recording in the context of a university extension course, which sets up the research scenario. This course was aimed at teachers and future mathematics teachers and addressed the possibilities of GeoGebra for teaching and learning of Plane and Spatial Geometries, in addition to promoting discussions on the integration of digital technologies in teaching. This present study focuses on a discussion that took place at one of the meetings of the course. This discussion was considered a collective interview and was analyzed in the light of qualitative processes. The results, which are presented through categories and subcategories, show that the students consider that digital technologies are important both in the learning of mathematical content and in the education of future teachers, but they evaluate that this theme has been neglected in their own education, and in the teaching Mathematics in Basic Education.
\end{abstract}

Keywords: Mathematics education. Prospective teacher education. Digital technologies.

\section{Para citar - (ABNT NBR 6023:2018)}

IDEM, Rita de Cássia; SILVA, Ricardo Scucuglia Rodrigues da. Tecnologias digitais no ensino e na formação docente segundo a visão de estudantes de licenciatura em matemática. Eccos - Revista Científica, São Paulo, n. 56, p. 1-20, e8501, jan./mar. 2021. Disponível em: https://doi.org/10.5585/eccos.n56.8501. 


\section{Introdução}

Desde a década de 1950, tem se refletido sobre a utilização das tecnologias digitais para fins educacionais. As primeiras iniciativas remetiam a uma perspectiva behaviorista, na qual o computador era utilizado como transmissor de conteúdos e o aluno era treinado para responder corretamente às questões que lhe eram propostas. Seymour Papert, que criticava essa visão, defendia que as tecnologias digitais possibilitam uma mudança de paradigma educacional. Para ele, o computador não deveria ser utilizado para melhorar a transmissão de conhecimento, mas, sim, para potencializar o aprendizado por meio da construção do conhecimento na interação com essas tecnologias. Essa ideia foi nomeada de Construcionismo. (VALENTE, 1999).

O Construcionismo foi o elemento principal da primeira fase das tecnologias digitais na Educação Matemática no Brasil, iniciada por volta de 1990, segundo Borba, Scucuglia e Gadanidis (2014). De acordo com esses autores, a Educação Matemática brasileira vivenciou quatro fases distintas do uso das tecnologias digitais. São elas: primeira fase - ideia de programação e Construcionismo; segunda fase - utilização de programas educacionais dedicados à exploração gráfica e geométrica; terceira fase - Educação à Distância Online, com foco na formação de professores; e, quarta fase - uso de redes sociais, produção de vídeos e GeoGebra. A partir desse panorama, observa-se a diversidade de ideias que permearam a integração das tecnologias digitais na Educação Matemática ao longo dos anos.

As justificativas de pesquisadores e de educadores que defendem a integração das tecnologias digitais no ensino de Matemática são muito variadas: o descompasso do papel da tecnologia digital na sociedade e seu papel na escola (MELLO, 2003; TEDESCO, 2015); a necessidade de preparação do estudante em formação para se posicionar criticamente em uma sociedade digital (KENSKI, 2003; NUNES et al., 2016); a possibilidade de uma mudança do aspecto tradicional e mecânico da aprendizagem para um aspecto dinâmico e construtivo (BORBA; VILLARREAL, 2005; BORBA; SCUCUGLIA; GADANIDIS, 2014), entre outras. Consideramos válidas todas essas justificativas, mas, neste artigo, voltamos nossa atenção para a posição dos futuros professores em relação a essa temática. Sendo assim, apresentamos e discutimos as visões de quatro estudantes de Matemática quanto à integração das tecnologias digitais no ensino e em sua formação docente.

Os dados aqui apresentados pertencem a um recorte de uma pesquisa que objetivou investigar a formação tecnológica de professores e futuros professores de Matemática, participantes de um curso de extensão universitária. $\mathrm{O}$ foco foi a exploração de atividades 
investigativas sobre Geometria Plana e Geometria Espacial utilizando o GeoGebra e a produção audiovisual envolvendo o uso de linguagens artísticas. Optamos em explorar, neste artigo, apenas parte dos dados produzidos. Os dados apresentados foram constituídos em um dos encontros do referido curso, no qual ocorreram debates e reflexões entre as participantes acerca do uso de tecnologias digitais em suas atuais práticas como alunas de graduação e futuras práticas docentes como professoras de Matemática. Antes de discutirmos os diálogos e as reflexões das estudantes, consideramos pertinente apresentar uma caracterização sobre o curso de extensão - cenário da pesquisa - e as opções metodológicas tomadas neste estudo.

\section{Curso de extensão universitária}

No mês de junho de 2016, em uma universidade pública paulista, houve o desenvolvimento de um curso de extensão universitária destinado a professores e futuros professores de Matemática. O curso foi intitulado "GeoGebra e Performance Matemática Digital" e objetivou apresentar as potencialidades do GeoGebra para o ensino e aprendizagem de Geometrias Plana e Espacial e introduzir a ideia de Performance Matemática Digital ${ }^{1}$ (PMD) como uma possibilidade de engajamento dos estudantes à aprendizagem.

O curso ocorreu em seis encontros de três horas cada, no período noturno, totalizando 18 horas de carga horária, e as atividades desenvolvidas foram diversificadas: exploração de atividades no GeoGebra, discussão sobre as tecnologias digitais no ensino, discussão sobre PMDs, desenvolvimento de atividades com o GeoGebra e produção de PMDs. Participaram do curso quatro professores e quatro estudantes de Licenciatura em Matemática.

O curso de extensão universitária foi cenário de investigação de três pesquisas de mestrado: uma buscou investigar o processo de desenvolvimento das atividades exploratórioinvestigativas sobre Geometria Espacial utilizando o software GeoGebra e que foram produzidas para serem exploradas durante o curso (HONORATO, V., 2018); outra pesquisa investigou o processo de produção de PMDs, num contexto de formação de professores para o ensino de Geometria com o GeoGebra (VITAL, 2018); e outro estudo focou na investigação dos conhecimentos mobilizados pelos participantes durante os encontros (IDEM, 2017), tendo como referenciais teóricos o construto Conhecimento Tecnológico Pedagógico de Conteúdo (Technological Pedagogical Content Knowledge - TPACK) (KOEHLER; MISHRA, 2009; MISHRA; KOEHLER, 2006) e o Construcionismo (PAPERT, 1993, 1980).

\footnotetext{
${ }^{1}$ Produção artística integrada ao uso das tecnologias digitais para comunicação de ideias matemáticas (SCUCUGLIA, 2014).
} 
Neste artigo, focamos na discussão sobre as tecnologias digitais ocorrida em um dos encontros do curso e, especificamente, sobre os dados provenientes das falas das estudantes de Licenciatura Matemática, buscando responder à seguinte questão: “Como as estudantes veem as tecnologias digitais em sua formação e na prática docente?". Com base nessa pergunta, objetiva-se apresentar e discutir o papel das tecnologias digitais na formação inicial e no ensino de Matemática, com base nas visões das estudantes. Entendemos que a formação universitária é um período de aprendizado dos futuros professores, no qual eles passam por uma dualidade de papéis: ao mesmo tempo que são alunos, começam a pensar criticamente sobre o ensino e refletir sobre ele, enquanto profissionais da educação em formação. Sendo assim, consideramos suas visões sobre o uso das tecnologias digitais elementos importantes e que caracterizam essa dualidade vivenciada. A seguir, apresentamos a metodologia empregada na produção e análise de dados, em busca de resposta à pergunta.

\section{Metodologia}

Esta investigação foi desenvolvida por meio da abordagem qualitativa. Segundo Bogdan e Biklen (1994), a pesquisa qualitativa se caracteriza por: ter o pesquisador como instrumento; possuir dados expressos em palavras ou imagens, ou seja, ser descritiva; possuir mais preocupação com o processo do que com seus resultados; possuir uma análise de dados indutiva, em que não se busca confirmar ou refutar hipóteses prévias; e focar no significado que as pessoas atribuem aos fenômenos estudados. Nas pesquisas qualitativas,

[...] privilegiam-se descrições de experiências, relatos de compreensões, respostas abertas a questionários, entrevistas com os sujeitos, relatos de observações e outros procedimentos que deem conta de dados sensíveis, de concepções, de estados mentais, de acontecimentos, etc. (BICUDO, 2013, p. 117).

As quatro estudantes participantes do estudo são: Alice, Helena, Laura e Sofia. Durante o desenvolvimento da pesquisa, Alice era aluna do segundo ano do curso de Licenciatura em Matemática, Helena era aluna do terceiro ano, e Laura e Sofia eram alunas do quarto ano. Esses nomes são fictícios, para preservar a identidade das participantes do estudo.

A produção dos dados se deu por meio de gravação em áudio da discussão ocorrida em um dos encontros do curso de extensão universitária supracitado. Essa discussão teve como tema a integração das tecnologias digitais no ensino de Matemática, bem como na formação de professores. Nesse encontro do curso, estavam presentes, também, dois 
professores de Matemática, que interagiram na discussão; entretanto, focaremos nos dados provenientes das falas das estudantes, que são o elemento central de nossa investigação.

A discussão, que caracteriza o objeto de estudo, é entendida como uma entrevista semiestruturada em grupo, pois a dinâmica da discussão ocorria com a utilização de temas ou questões incitadoras. Segundo Oliveira (2007, p. 86), “A entrevista é um excelente instrumento de pesquisa por permitir a interação entre pesquisador(a) e entrevistado(a) e a obtenção de descrições detalhadas sobre o que se está pesquisando".

A produção de dados por meio de entrevistas pode ocorrer de forma individual ou em grupos (LÜDKE; ANDRÉ, 2011; GASKELL, 2008). De acordo com Gaskell (2008), na entrevista, as palavras são a principal forma de troca, ela se configura uma interação, por meio da qual ocorre produção de conhecimentos; segundo ele

Toda pesquisa com entrevista é um processo social, uma interação ou um empreendimento cooperativo, em que as palavras são o meio principal de troca. Não é apenas um processo de informação de mão única passando de um (o entrevistado) para outro (o entrevistador). Ao contrário, ela é uma interação, uma troca de ideias e de significados, em que várias realidades e percepções são exploradas e desenvolvidas. Com respeito a isso, tanto o(s) entrevistado(s) como o entrevistador estão, de maneiras diferentes, envolvidos na produção de conhecimento. (GASKELL, 2008, p. 73).

A dinâmica da discussão ocorreu da seguinte forma: os participantes foram divididos em duplas e cada dupla ficou responsável pela leitura de uma parte do texto "Educação Matemática na Era Digital" de Abar (2011), e por responder a questões referentes ao texto. No final, cada dupla socializava a parte lida do texto e, nesse momento, ocorria o processo de discussão, em que as estudantes partilhavam suas experiências em relação à integração das tecnologias digitais no ensino de Matemática e suas percepções em relação à sua própria formação e ao contexto educacional.

A análise de dados ocorre em

[...] um processo continuado em que se procura identificar dimensões, categorias, tendências, padrões, relações, desvendando-lhes o significado. Este é um processo complexo, não linear, que implica um trabalho de redução, organização e interpretação dos dados que se inicia já na fase exploratória e acompanha toda a investigação. (ALVES-MAZZOTTI; GEWANDSZNADJER, 2001, p. 170).

Para analisar os dados provenientes da discussão, entendida como uma entrevista semiestruturada em grupo, ocorreu um processo de transcrição, de modo a incluir "[...] todas as palavras faladas, mas não as características paralingüísticas.” (GASKELL, 2008, p. 85). Em seguida, o texto produzido foi lido e relido, com a intenção de buscar elementos com 
potencial de responder à questão diretriz. Os dados, então, foram organizados em categorias emergentes (LÜDKE; ANDRÉ, 2011), as quais serão apresentadas a seguir.

\section{As visões das estudantes sobre as tecnologias digitais}

Nesta seção, apresentamos a sistematização dos dados em categorias emergentes. Inicialmente, considerando a dualidade vivida pelas estudantes, a organização dos dados ocorreu em duas categorias gerais: Formação e Escola. Na categoria Formação, estão reunidas subcategorias emergentes em que as estudantes manifestaram percepções de como a sua formação se encontra no contexto da integração das tecnologias digitais. Na categoria Escola, estão reunidas subcategorias em que as futuras docentes manifestam suas percepções acerca da integração das tecnologias digitais na Educação Básica e as implicações disso.

\subsection{Formação}

Nesta categoria, foram identificadas três subcategorias emergentes. A primeira delas é chamada Uso da tecnologia digital. Nessa subcategoria estão os momentos em que as estudantes refletem sobre como ocorre o uso da tecnologia digital nas disciplinas do curso de Licenciatura em Matemática. A segunda subcategoria foi identificada como Avaliação da formação tecnológica, na qual estão reunidas falas em que as estudantes avaliam se a forma como seu curso é constituído as preparam para a integração das tecnologias digitais no ensino de Matemática. A terceira subcategoria foi classificada como Possibilidades das tecnologias digitais. Nela, as estudantes refletem sobre como seu aprendizado e formação seriam potencializados com o uso das tecnologias digitais.

\section{- Uso da tecnologia digital}

As estudantes apontaram que, de certa forma, ocorre alguma preocupação da universidade com sua formação tecnológica. Segundo Helena, existe uma disciplina optativa sobre a integração das tecnologias digitais no ensino de Matemática na grade curricular do curso. De acordo com a estudante, essa disciplina a auxiliou no entendimento da integração das tecnologias digitais, entretanto apenas essa disciplina possui esse enfoque. 
Helena: Mas se a gente for pensar no nosso caso, tem uma disciplina, que é optativa. Ela auxilia bastante a aprender a trabalhar com vários recursos tecnológicos, desde histórias em quadrinhos aplicando matemática, música, pintura, tudo envolvendo o computador, envolvendo softwares; mas só. Se eu também não tivesse feito essa disciplina, eu nem saberia.

Costa et al. (2008) apontam que a formação tecnológica do professor, muitas vezes, é deficiente. Segundo os autores, as instituições responsáveis pela educação docente oferecem disciplinas específicas sobre a aprendizagem do uso das tecnologias digitais, mas não integram à aprendizagem das demais disciplinas curriculares. $\mathrm{O}$ que as universidades, responsáveis pela formação inicial de professores,

[...] tipicamente oferecem se circunscreve à realização de um determinado curso ou conjunto de sessões de formação relacionadas com a aprendizagem das próprias tecnologias, não implicando necessariamente a sua utilização do ponto de vista curricular, pelos alunos. Já à saída das instituições de formação, das quais seria de esperar a aposta numa preparação que permitisse aos professores fazerem face a uma realidade social e profissional em que os computadores proliferam, muitos dos futuros professores acabam por sair dessas instituições com uma preparação desadequada ou pelo menos insuficiente em relação à exploração e uso do potencial das tecnologias na aprendizagem dos alunos. (COSTA et al., 2008, p. 42).

De acordo com as estudantes, existem outras disciplinas, de cunho matemático, que também tratam da integração das tecnologias digitais no ensino. Segundo Sofia, alguns professores com formação em Educação Matemática se preocupam em utilizar tecnologias digitais em suas aulas, mas esse uso ocorre de forma superficial, no qual os alunos observam objetos matemáticos em programas, entretanto, não aprendem a utilizá-los.

Sofia: Os professores que são da Educação Matemática esses tentam usar um pouquinho [de tecnologia]. De vez em quando, o GeoGebra, mas não aprendemos a usar tecnologia. Em Geometria, os professores mostram as construções geométricas em 3D. Mostram o controle deslizante e o prisma rodando no $3 D$, por exemplo, mas só. É basicamente isso que acontece.

Vemos, pela experiência de Sofia, que sua formação se ocupou, ao menos em partes, com a integração da perspectiva tecnológica e de conteúdo (MISHRA; KOEHLER, 2006). Entretanto, a estudante sentiu que apenas relacionar conhecimentos matemáticos e tecnológicos não é suficiente para sua formação enquanto docente. De fato, Mishra e Koehler (2006) argumentam que a formação tecnológica do professor deve ocorrer de forma a construir conhecimentos tecnológicos, pedagógicos e de conteúdo específico de forma integrada. Segundo os autores, para que os professores possam integrar as tecnologias digitais no ensino, eles necessitam desenvolver um Conhecimento Tecnológico Pedagógico de Conteúdo (TPACK). Destacamos, nesse sentido, a relevância formativa da participação de 
futuros professores em cursos de extensão universitária como este desenvolvido na presente pesquisa.

O TPACK está fundamentado na ideia de que a integração da tecnologia - digital ou não - na educação ou na formação do professor deva ser acompanhada de uma fundamentação conceitual (Conhecimento de Conteúdo), ou seja, se utilizar de conhecimentos específicos da matéria a que se destina; e de um aspecto pedagógico (Conhecimento Pedagógico), isto é, que tenha características propícias para os objetivos do ensino e da aprendizagem. Sendo assim, para que o professor possa integrar tecnologias na sala de aula, ele deve desenvolver um conhecimento integrado de tecnologia, conteúdo e pedagogia, como apontam Sampaio e Coutinho (2014, p. 6):

O desenvolvimento de um tópico por parte de um professor em contexto de sala de aula requer um cruzamento de todas as três principais fontes de conhecimento: tecnologia, pedagogia e conteúdo, sendo fundamental a interligação destes componentes com o intuito de se desenvolver o TPACK e provocar uma efetiva alteração na prática letiva dos professores.

\section{- Avaliação da formação tecnológica}

Durante a discussão, as estudantes avaliaram a maneira como o curso de Licenciatura em Matemática as estão preparando para a integração das tecnologias digitais no ensino. Segundo Laura, o curso não a prepara para os desafios do uso das tecnologias digitais e que a disciplina mencionada por Helena não é suficiente.

Laura: Eu acho que a gente não está preparada. A gente vê pelo nosso curso que a gente não tem nada disso [enfoque na integração das tecnologias]. A gente teve uma disciplina que foi optativa. E este ano já não teve.

A estudante ainda cita que a ênfase ao uso das tecnologias digitais ocorre nas aulas de disciplinas pedagógicas, mas que nas aulas de conteúdo matemático não ocorrem.

Laura: A gente vê um pouquinho [de uso de tecnologia] nas aulas de licenciatura, nas matérias que são da licenciatura, já nas [disciplinas] do bacharel [de conteúdo matemático], a gente não vê.

Sendo assim, verifica-se uma separação da constituição do conhecimento matemático em relação aos conhecimentos pedagógicos e tecnológicos, como também reportado por Mishra e Koehler (2006). Segundo os autores, o conhecimento tecnológico é explorado de forma disjunta dos conhecimentos tecnológicos e de conteúdo, nos cursos de formação de professores. Sendo assim, é necessário explorar o TPACK na formação de professores. Essa forma de conhecimento 
[...] compreende as representações de conceitos utilizando tecnologias; técnicas pedagógicas que aplicam tecnologias de forma construtiva para ensinar conteúdos de forma diferenciada de acordo com as necessidades de aprendizagem dos alunos; conhecimento do que torna os conceitos difíceis ou fáceis de aprender e como a tecnologia pode ajudar a corrigir desafios conceituais; conhecimento da compreensão e dos pressupostos epistemológicos do conteúdo anterior dos alunos; e conhecimento de como as tecnologias podem ser usadas para construir a compreensão existente para desenvolver novas epistemologias ou fortalecer as antigas. (MISHRA; KOEHLER, 2008, p. 2, tradução nossa).

\section{- Possibilidades das tecnologias digitais}

As estudantes discutiram também sobre como sua formação poderia ser complementada se houvesse o uso das tecnologias digitais. Essa formação, segundo elas, iria além do uso em sala de aula, beneficiando seu próprio aprendizado. Alice expõe um exemplo da dificuldade de entendimento de conceitos matemáticos e como a utilização da tecnologia digital poderia minimizar tais dificuldades.

Alice: O exemplo que eu tenho é na aula de Geometria Euclidiana. Hoje a gente viu a área da esfera e a área da superfície esférica, que é só a casquinha. Para montar a área da superfície esférica, a gente usa o que chama de coroa. A coroa é um cilindro formando dois cones. $O$ cilindro menos os cones, dá a superfície esférica, dá a área da esfera. E eu não conseguia ver isso de jeito nenhum. A professora tentava desenhar, tentava desenhar, e no final eu aceitei que a área era igual. Mas, se ela utilizasse algum software, eu conseguiria visualizar.

Identificamos que Aline pôde perceber as potencialidades de visualização das tecnologias digitais, como as exploradas no curso de extensão universitária que foi participante. Destacamos, ainda, as potencialidades do GeoGebra em termos de visualização e experimentação na produção de significados e aprendizagem matemática. Essa percepção a fez avaliar seu próprio processo de aprendizagem da Matemática, que seria beneficiado se houvesse a exploração da visualização por meio das tecnologias digitais. Segundo Borba e Villarreal (2005), a visualização é uma forma alternativa de construir o conhecimento matemático. Sendo assim, as tecnologias digitais, com seu apelo visual, podem contribuir para a visualização matemática, entendida como “[...] o processo de formação de imagens (mentalmente, ou com lápis e papel, ou com o auxílio da tecnologia) e utilização eficaz dessas imagens.” (ZIMMERMANN; CUNNINGHAM, 1991, p. 3, tradução nossa). 


\subsection{Escola}

Nesta categoria de análise, foram também identificadas três subcategorias emergentes. $\mathrm{Na}$ primeira delas, Benefícios ao aprendizado, estão reunidas as reflexões acerca dos benefícios das tecnologias digitais ao aprendizado dos alunos. A segunda subcategoria, identificada como $\mathbf{O}$ professor no contexto das tecnologias digitais, reúne os momentos em que as estudantes demonstraram suas visões a respeito do papel do professor e de seu preparo para a integração das tecnologias digitais. A terceira subcategoria, por fim, classificada como Obstáculos à integração das tecnologias digitais no ensino, reúne os entendimentos das licenciandas sobre o motivo de haver pouca ênfase ao ensino com tecnologias digitais na Educação Básica.

\section{- Benefícios ao aprendizado}

Considerando a experiência vivida pelas estudantes no curso de extensão universitária, no qual elas puderam explorar a Geometria Plana e a Geometria Espacial utilizando o GeoGebra, elas acreditam que as tecnologias digitais podem trazer benefícios à aprendizagem dos alunos. Helena aponta que o GeoGebra possibilita outras formas de visualizar relações matemáticas, as quais seriam dificilmente entendidas com as tecnologias comumente utilizadas no ensino, como lousa e giz.

Helena: Eu acho que [tecnologia digital] beneficia sim [o aprendizado]. A gente, aqui mesmo, viu que no GeoGebra, a gente consegue enxergar. Manipulando o GeoGebra, consegue enxergar muitas coisas que, se fossem num quadro, a gente não conseguiria.

No contexto digital, a aprendizagem pode ser potencializada por meio da investigação e da exploração (PONTE, 1995; BORBA; SCUCUGLIA; GADANIDIS, 2014), as quais permitem aos alunos uma relação com a Matemática significativamente diferente da abordagem mecânica. As tecnologias digitais têm ocasionado

[...] um crescendo de interesse pela realização de projectos e actividades de modelação, investigação e exploração pelos alunos, como parte fundamental da sua experiência matemática; [e] uma demonstração prática da possibilidade de envolver os alunos em actividade matemática intensa e significativa, favorecendo o desenvolvimento de atitudes positivas em relação a esta disciplina e uma visão muito mais completa da sua verdadeira natureza. (PONTE, 1995, p. 2).

Além disso, as tecnologias digitais possibilitam ao ensino e à aprendizagem da Matemática “[...] uma relativização da importância das competências de cálculo e de simples manipulação simbólica, que podem ser realizadas agora muito mais rápida e eficientemente 
[...]” (PONTE, 1995, p. 2), sendo assim os cálculos mecânicos já não são obstáculos com o uso de calculadoras, aplicativos de celulares, ou programas de computador. As tecnologias digitais também oferecem “[...] um reforço do papel da linguagem gráfica e de novas formas de representação, permitindo novas estratégias de abordagem dos mais variados problemas [...]” (PONTE, 1995, p. 2). Essa possibilidade é visível com o desenvolvimento da Geometria Dinâmica, que possibilita novas formas de manipulação e entendimento da Geometria, e com a criação de programas de edição de planilhas, os quais apresentam maneiras diversas de exploração da Estatística e da Matemática Financeira.

A facilidade de cálculos e as novas representações do conhecimento possibilitadas pelas tecnologias digitais fazem com que os alunos possam explorar conhecimentos matemáticos mais sofisticados, diminuindo os pré-requisitos para a aprendizagem de determinados conteúdos. Ponte $(1995$, p. 2) aponta que o uso da tecnologia digital requer “[...] uma atenção redobrada às capacidades intelectuais de ordem mais elevada, que se situam para além do cálculo e da simples compreensão de conceitos e relações matemáticas [...]”.

$\mathrm{Na}$ fala da estudante ainda se percebe que a experiência que lhe foi possibilitada pelo curso de extensão universitária a fez refletir sobre a sua aprendizagem e também sobre a aprendizagem dos alunos, de forma geral. Entender que as tecnologias digitais possibilitam uma nova maneira de se aprender e de se ensinar é o primeiro passo para que os professores possam integrar as tecnologias digitais no ensino. Corroborando essa ideia, Valente (1999, p. 12) aponta que o professor precisa " [...] entender o computador como uma nova maneira de representar o conhecimento, provocando um redimensionamento dos conceitos já conhecidos e possibilitando a busca e compreensão de novas idéias e valores.”.

\section{- O professor no contexto das tecnologias digitais}

As estudantes apontaram que o papel do professor se modifica no contexto do uso das tecnologias digitais, entretanto, elas não substituem o professor. Segundo Helena, o professor tem um papel fundamental no ensino com tecnologias digitais.

Helena: Os recursos tecnológicos vêm para ajudar o professor, ajudar o aluno aprender e não substituir o professor. Então eu acho que o professor tem o seu papel, que é principal, fundamental.

Segundo Assmann (2000, p. 7), “As novas tecnologias não substituirão o (a) professor(a), nem diminuirão o esforço disciplinado do estudo.”. Essas tecnologias 
[...] ampliam as possibilidades de se ensinar e aprender, oferecendo novas e variadas formas para que esses processos ocorram, de forma que idéias para trabalhos pedagógicos que antes eram inviáveis (por limitações de custo, tempo, recursos físicos, etc.) tornam-se factíveis com o uso de tecnologias. Essa é uma das formas pelas quais as tecnologias desafiam a educação e a desestabilizam, pois oferecem a oportunidade de uma prática que potencialmente pode ser melhor que a praticada, considerando a sociedade em que vivemos. (MALTEMPI, 2008, p. 60).

As estudantes também refletiram sobre a preparação do professor para integrar as tecnologias digitais. Segundo Laura, para que ele possa integrar, deve estar preparado para enfrentar novos desafios.

Laura: $O$ professor tem, primeiramente, que estar aberto a novos desafios, porque vão surgir dúvidas, vão surgir desafios. A formação, também, tem que ser muito sólida.

Para enfrentar desafios na integração das tecnologias digitais é necessário que o professor saia da zona de conforto e entre em uma zona de risco. Como apontam Borba e Penteado (2007, p. 56-57, grifo dos autores),

\begin{abstract}
Alguns professores procuram caminhar numa zona de conforto onde quase tudo é conhecido, previsível e controlável. [...] Esses professores nunca avançam para o que chamamos de zona de risco, na qual é preciso avaliar constantemente as consequências das ações propostas.
\end{abstract}

A ideia referente à zona de risco também aparece na fala de Alice. Segundo ela, a utilização de programas educacionais na aula ocasiona bastante dificuldade; ela acredita, inclusive, que essa dificuldade seja causada pela necessidade de ensinar o aluno a utilizar o programa antes de utilizá-lo para aprender Matemática.

\begin{abstract}
Alice: Para usar as tecnologias, o professor tem que planejar algo diferente, que vai dar um pouco mais de trabalho. $O$ material manipulativo talvez seja mais fácil: mostra para as crianças, dá para manipular algumas coisas e pronto. $O$ software que dá um pouco mais de trabalho, porque tem tudo aquilo de ensinar como mexer, para depois ensinar; porque a pessoa já tem que saber funções e outras coisas pra chegar no software.
\end{abstract}

Borba e Penteado (2007) discutem os desafios a serem enfrentados pelos professores que se aventuram na zona de risco da integração das tecnologias digitais ao ensino. Segundo os autores, esses riscos estão ligados à perda do controle da turma, à obsolescência do professor, aos problemas técnicos que podem ocorrer ao usar as tecnologias digitais, aos diversos caminhos de exploração que podem causar dúvida ao professor. Entretanto, eles argumentam que ao se aventurar na zona de risco, o professor pode desfrutar, juntamente com seus alunos, das potencialidades das tecnologias digitais. Eles apontam que "Aspectos como incerteza e imprevisibilidade [...] podem ser vistos como possibilidades para o 
desenvolvimento: desenvolvimento do aluno, desenvolvimento do professor, desenvolvimento das situações de ensino e aprendizagem.” (BORBA; PENTEADO, 2007, p. 66).

\section{- Obstáculos à integração das tecnologias digitais no ensino}

Outro ponto da discussão do uso das tecnologias digitais no ensino, foi a questão dos obstáculos existentes a essa utilização. As estudantes apontaram que faltam recursos nas escolas para que essa integração ocorra.

Helena: A escola não está capacitada. Os recursos tecnológicos envolvem, muitas vezes, a internet, que a escola não tem disponível. Não tem nem computadores para a formação dos alunos.

Laura: Falta tecnologia na escola. Muitas escolas que não têm internet. A Escola $X^{2}$ mesmo, é bem restrita. Às vezes tem, às vezes não. Em escola pública não tem computador para todo mundo.

Corroborando a falta de recursos materiais, Laura aponta para o fato de que existe um número excessivo de alunos nas salas de aulas das escolas públicas de Educação Básica, dificultando o trabalho do professor.

Laura: Também tem problema de as salas serem lotadas de alunos. Então, como é que o professor vai passar alguma coisa e vai ver, vai ajudar, com um monte de aluno, com às vezes três no mesmo computador e sei lá quantos, quarenta alunos numa sala? É muito difícil.

A precariedade de recursos disponíveis nas escolas para a integração das tecnologias digitais no ensino foi também apontada por Javaroni e Zampieri (2015). As autoras discutiram resultados parciais do Projeto Mapeamento, um mosaico de pesquisas que buscava investigar a utilização das tecnologias digitais nas escolas estaduais paulistas dos anos finais do Ensino Fundamental. Segundo elas, “[...] na maior parte dos laboratórios [de informática] visitados, há distintos empecilhos que inviabilizam o seu uso, tais como: número insuficiente de computadores por número de alunos, computadores inoperantes, [...] entre outros." (JAVARONI; ZAMPIERI, 2015, p. 1008).

A estudante ainda aponta que a exclusão digital é outro fator dificultador da utilização das tecnologias digitais para o ensino e para a aprendizagem. De acordo com Laura, a falta de recursos na escola não é superada pelos recursos disponíveis aos alunos fora da escola.

\footnotetext{
${ }^{2}$ Escola estadual localizada na mesma cidade onde a pesquisa foi realizada, na qual a estudante era estagiária do PIBID (Programa Institucional de Bolsas de Iniciação à Docência) durante sua participação na pesquisa.
} 
Laura: Às vezes, o aluno sai da escola e não tem, em casa, um computador. Tem celular também, todo mundo tem hoje em dia, mas às vezes não dá para baixar [os aplicativos específicos], não dá para fazer certinho. Então, o ideal é ter um computador.

Segundo Sorj e Guedes (2005, p. 102), a exclusão digital "[...] diz respeito às consequências sociais, econômicas e culturais da distribuição desigual do acesso a computadores e Internet.". A inclusão digital, nesse sentido, se configura no "[...] acesso de todo e qualquer cidadão às tecnologias digitais, possibilitando-os a capacidade de estar conectados em rede e a partir deste contexto ter acesso a informação e consequentemente produzir conhecimento." (CARNEIRO; SILVA, 2012, p. 3). Assim, verifica-se que a desigualdade social impede a inclusão digital fora da escola e a falta de recursos na escola, perpetua a exclusão digital dentro da instituição de ensino. Para Sorj e Remold (2005) é necessário que existam políticas de inclusão. Segundo eles,

A luta pela inclusão digital é uma luta contra o tempo. Novas tecnologias da informação aumentam desigualdades sociais existentes e as políticas para inclusão digital nada mais são que uma luta para re-igualar as possibilidades de acesso ao mercado de trabalho e as condições de vida. (SORJ; REMOLD, 2005, p. 15).

Mas os obstáculos percebidos pelas estudantes vão além da falta de recursos. Segundo elas, a forma como o currículo educacional é organizado dificulta o trabalho do professor. Segundo as estudantes, cada vez mais se inserem tópicos a serem ensinados aos alunos e, com isso, o professor passa a ter menos autonomia de como organizar a sua aula e, consequentemente, a utilizar propostas de integração das tecnologias digitais.

Laura: Tem o exemplo também do uso do caderninho ${ }^{3}$. Ele limita muito o professor a fazer qualquer coisa. Qualquer aula diferente, qualquer matéria diferente, então, qualquer uso de software diferente vai ficar bem apertado [para terminar o conteúdo planejado].

Sofia: Então, resumindo, eu acho que tudo interfere [na integração das tecnologias digitais]. Tudo, desde a estrutura da escola, ao currículo que o professor tem que seguir.

Laura: Lá no PIBID, a gente vê bastante isso, que eles colocam cada vez mais tópicos. Cada vez fica mais apertado para cumprir o programa. Quando chega no final [do ano] não dá realmente para dar todo o conteúdo.

Segundo Gatti, Barreto e André (2011, p. 39), as propostas curriculares condicionam a existência de avaliações externas ao ensino; segundo os autores, “[...] acentuam-se as preocupações com a eficácia e a eficiência das escolas no manejo das políticas de currículo.”. E, com isso, passa-se a medir a qualidade da educação por meio dos rendimentos nas ${ }^{3}$ O "caderninho" é o material didático disponibilizado pelo Estado de São Paulo aos alunos das escolas estaduais. Ele determina os conteúdos a serem
trabalhados em cada bimestre letivo. 
avaliações. Dessa forma, o currículo, mesmo não sendo imposto, pode influenciar a autonomia do professor, como aponta Honorato, A. (2016, p. 131): “[...] imposições veladas ou não em torno do currículo podem não favorecer o protagonismo dos estudantes e não dar ao professor a liberdade para moldar suas aulas e o currículo conforme a realidade de seus alunos e da escola.", dificultando a ele integrar as tecnologias digitais ao ensino.

Por fim, as estudantes apontaram que as concepções tradicionais de como devem ser o ensino e a aprendizagem são obstáculos à integração das tecnologias digitais.

Laura: E também tem a barreira criada pela escola. Quais as escolas que vêm com bons olhos as coisas novas [tecnologias digitais]?

Sofia: Pelo menos, algumas escolas particulares são abertas [às inovações]. Mas a maior parte das escolas são assim: "apareceu um aplicativo novo que vai ser super útil, vamos dar um tablet pra todo mundo"; "não, eles aprendem na lousa, por que usar tablet?". Geralmente é assim. Eles não aceitam uma nova tecnologia.

Segundo Imbernón (2015, p. 76), as mudanças ocorridas na sociedade causadas pelas tecnologias digitais “[...] se refletem na mudança inevitável das formas de pensar, sentir e atuar das novas gerações e que fizeram mudar o papel das escolas (ou deveriam fazê-las mudar) e as funções dos docentes.”. O papel das escolas deveria mudar, uma vez que as tecnologias digitais possibilitam o acesso ao conhecimento, tirando da escola e dos professores o status de "detentores do conhecimento". Mas, o que se vê, muitas vezes, é a reprodução das mesmas práticas de ensino de muito antes do advento das tecnologias digitais, como observa Prado (1998, p. 2): “O modelo educacional ainda é baseado na transmissão de conhecimento, o qual concebe o aluno passivo, sem capacidade crítica e reflexiva, com uma visão de mundo segundo a que lhe foi transmitida.".

Algumas das razões foram apontadas pelas estudantes, como a falta de recursos, a falta de preparo do professor, o excesso de alunos, o currículo limitante da autonomia; mas elas perceberam também a resistência à mudança. Essa resistência vai além do conceito de zona de risco, é uma resistência de ordem epistemológica, uma vez que a forma tradicional aparentemente é eficaz para os propósitos educacionais, as inovações não são vistas como positivas.

Papert (1993) explica que, inicialmente, os computadores eram situados nas salas de aulas e que, com o passar do tempo, surgiram as salas de informática. Segundo o autor, 


\begin{abstract}
A mudança de um instrumento radicalmente subversivo na sala de aula para um instrumento conservador embotado no laboratório de informática não veio nem da falta de conhecimento nem da falta de software. Eu explico por uma inteligência inata da Escola, que agiu como qualquer organismo vivo em defender-se contra um corpo estranho. Pôr em movimento uma reação imune cujo o resultado final seria digerir e assimilar o intruso. (PAPERT, 1993, p. 39-40, tradução nossa).
\end{abstract}

Apenas a existência de recursos não garante a integração das tecnologias digitais ao ensino. É necessária uma mudança nas concepções de ensino e de aprendizagem de professores e gestores escolares, também de políticas públicas que suportem a mudança e de formação adequada aos professores.

\title{
5 Considerações finais
}

As tecnologias digitais passaram por diversos usos na pesquisa em Educação Matemática, sendo caracterizados em quatro fases distintas. Entretanto, a integração dessas mídias na formação docente e no ensino tem sido negligenciada.

Neste artigo, discutimos como quatro estudantes de Licenciatura em Matemática veem a integração dessas tecnologias tanto no ensino, quanto em sua própria formação. Os dados provenientes das falas das estudantes foram produzidos em um dos encontros de um curso de extensão universitária, destinado a professores e futuros professores de Matemática, focado na exploração de Geometrias Plana e Espacial com o GeoGebra.

A análise dos dados revelou duas categorias distintas em relação à visão das estudantes: Formação e Escola. Na primeira categoria, estão expressas as visões das estudantes sobre sua formação para a integração das tecnologias digitais. Na segunda categoria, se encontram as visões das estudantes sobre a integração das tecnologias digitais no ensino de Matemática.

A categoria Formação foi dividida em três subcategorias. Na subcategoria Uso da tecnologia digital, as estudantes refletiram sobre a concentração do uso das tecnologias digitais em apenas algumas disciplinas específicas em seus cursos ou a pouca ênfase da exploração dessas mídias nas disciplinas focadas na Matemática. Na subcategoria Avaliação da formação tecnológica, as futuras professoras discutem seu sentimento de despreparo para a integração das tecnologias digitais. Por fim, na subcategoria Possibilidades das tecnologias digitais, elas observam como a integração das tecnologias digitais em sua formação poderia facilitar seu próprio aprendizado em relação a conceitos matemáticos. Essa categoria revela a preocupação das estudantes em relação à sua formação tecnológica. Em sua visão, as tecnologias digitais deveriam ser mais integradas em todas as disciplinas, para que pudessem 
contribuir com seu aprendizado em relação à Matemática e em relação à sua preparação para a utilização das tecnologias digitais em suas futuras práticas docentes.

Da categoria Escola também emergiram três subcategorias de dados. Na subcategoria Benefícios ao aprendizado, as estudantes refletem sobre as novas possibilidades de exploração da Matemática causadas pelas tecnologias digitais. Na subcategoria $\mathbf{O}$ professor no contexto das tecnologias digitais, elas discutem o papel dos professores frente às tecnologias digitais, os quais devem sair de sua zona de conforto do ensino transmissivo e planejar algo diferente de suas aulas que ocorrem sem as tecnologias; segundo elas, esse processo pode apresentar dificuldades aos docentes. Na subcategoria Obstáculos à integração das tecnologias digitais no ensino, as futuras professoras observam as dificuldades encontradas na integração das tecnologias digitais, como a falta de recursos, a superlotação de sala de aulas, a exclusão digital, o engessamento do currículo e a intolerância à mudança. Com base nessa categoria, observamos que as estudantes consideram a integração das tecnologias digitais importantes para o aprendizado matemático dos alunos, mas ponderam que os professores e as escolas estão despreparados para essa integração.

Em conclusão, as estudantes veem a integração das tecnologias digitais no ensino e na formação de professores como um importante aspecto formativo e de aprendizagem. Entretanto, elas observam que essa integração tem sido negligenciada em sua formação e na escola.

Buscamos, por meio deste texto, apresentar a posição de estudantes em relação às instâncias da integração das tecnologias digitais no ensino. Consideramos de extrema importância ouvir aqueles que são diretamente influenciados pelos processos de ensino, de aprendizagem e de formação. Mas ainda nos inquietamos: o que pensam os professores sobre a integração das tecnologias digitais no ensino de Matemática? Qual a visão dos estudantes da Educação Básica? Qual a posição da comunidade? Esperamos, portanto, que as discussões aqui apresentadas possam contribuir para maior entendimento de como as tecnologias digitais são compreendidas no contexto educacional. 


\section{Referências}

ABAR, C. A. A. P. Educação Matemática na Era Digital. Unión, San Cristobal de La Laguna, v. 27, p. 14-28, 2011.

ALVES-MAZZOTI, A, J; GEWANDSZNAJDER, F. O método nas ciências naturais e sociais: pesquisa quantitativa e qualitativa. São Paulo: Pioneira, 2001.

ASSMANN, H. A metamorfose do aprender na sociedade da informação. Ciência da Informação, Brasília, v. 29, n. 2, p. 7-15, maio/ago. 2000.

BICUDO, M. A. V. Pesquisa qualitativa e pesquisa qualitativa segundo a abordagem fenomenológica. In: BORBA, M. C.; ARAÚJO, J. L. (org.). Pesquisa Qualitativa em Educação Matemática. 5. ed. Belo Horizonte: Autêntica, 2013. p. 111-124.

BOGDAN, R.; BIKLEN, S. Investigação qualitativa em educação: uma introdução à teoria dos métodos. Porto: Porto, 1994.

BORBA, M. C.; PENTEADO, M. G. Informática e Educação Matemática. 3. ed. Belo Horizonte: Autêntica, 2007.

BORBA, M. C.; VILLARREAL, M. E. Humans-with-media and the reorganization of mathematical thinking: information and communication technologies, modeling, visualization, and experimentation. New York: Springer Science, 2005.

BORBA, M. C.; SCUCUGLIA, R.; GADANIDIS, G. Fases das tecnologias digitais em Educação Matemática: sala de aula e internet em movimento. Belo Horizonte: Autêntica, 2014.

CARNEIRO, G. B.; SILVA, J. L. C. Políticas públicas de inclusão digital no contexto da educação escolar como fator de acesso a informação. In: ENCONTRO REGIONAL DE ESTUDANTES DE BIBLIOTECONOMIA, DOCUMENTAÇÃO, CIÊNCIA E GESTÃO DA INFORMAÇÃO, 15., 2012, Juazeiro do Norte. Anais [...]. Juazeiro do Norte: EREBD, 2012. p. 1-11.

COSTA, F. A.; RODRIGUES, A.; PERALTA, M. A.; RAMOS, J.; SEBASTIÃO, L.; MAIO, V.; DIAS, P.; GOMES, M. J.; RAMOS, A.; VALENTE, L.; CRUZ, E.; REIS, O.

Competências TIC. Estudo de Implementação. Lisboa: Gabinete de Estatística e Planeamento da Educação, 2008.

GASKELL, G. Entrevistas individuais e grupais. In: BAUER, M. W.; GASKELL, G. Pesquisa qualitativa com texto, imagem e som: um manual prático. Tradução: GUARESCHI, P. A. 7. ed. Petrópolis: Vozes, 2008. p. 64-89.

GATTI, B. A.; BARRETO, E. S. S.; ANDRÉ, M. E. D. A. Políticas docentes no Brasil: um estado da arte. Brasília: UNESCO, 2011. 
HONORATO, A. H. A. Modelagem Matemática e o material didático do Estado de São Paulo: diálogos em um trabalho com licenciandos. 2016. Dissertação (Mestrado em Educação Matemática) - Universidade Estadual Paulista, Rio Claro, 2016.

HONORATO, V. S. Elaborando atividades matemáticas com o software GeoGebra. 2018. Dissertação (Mestrado em Educação Matemática) - Universidade Estadual Paulista, Rio Claro, 2018.

IDEM, R. C. Construcionismo, conhecimentos docentes e GeoGebra: uma experiência envolvendo licenciandos em Matemática e professores. 2017. Dissertação (Mestrado em Educação Matemática) - Universidade Estadual Paulista, Rio Claro, 2017.

IMBERNÓN, F. Novos desafios da docência no século XXI: a necessidade de uma nova formação docente. In: SILVA JUNIOR, C. A.; GATTI, B. A.; MIZUKAMI, M. G. N; PAGOTTO, M. D. S.; SPAZZIANI, M. L. (org.). Por uma revolução no campo de formação de professores. São Paulo: Editora Unesp, 2015. p. 75-82.

JAVARONI, S. L.; ZAMPIERI, M. T. O Uso das TIC nas Práticas dos Professores de Matemática da Rede Básica de Ensino: o Projeto Mapeamento e seus Desdobramentos. Bolema, Rio Claro (SP), v. 29, n. 53, p. 998-1022, dez. 2015.

KENSKI, V. M. Tecnologias e ensino presencial e a distância. Campinas: Papirus, 2003.

KOEHLER, M. J.; MISHRA, P. What Is Technological Pedagogical Content Knowledge? Contemporary Issues in Technology and Teacher Education, Charlottesville, v. 9, n. 1, p. 6070, 2009.

LÜDKE, M.; ANDRÉ, M. E. D. A. Pesquisa em Educação: abordagens qualitativas. 13. reimp. Rio de Janeiro: E.P.U., 2011.

MALTEMPI, M. V. Educação matemática e tecnologias digitais: reflexões sobre prática e formação docente. Acta Scientiae, Canoas, v. 10, n. 1, p. 59-67, jan./jun. 2008.

MELlO, G. N. Magistério De $1^{\circ}$ Grau: Da Competência Técnica Ao Compromisso Político. São Paulo: Cortez, 2003.

MISHRA, P.; KOEHLER, M. J. Technological pedagogical content knowledge: A framework for teacher knowledge. Teachers College Record, New York, v. 108, n.6, p.1017-1054, jun. 2006.

MISHRA, P.; KOEHLER, M. J. Introducing Technological Pedagogical Content Knowledge. In: ANNUAL MEETING OF THE AMERICAN EDUCATIONAL RESEARCH ASSOCIATION, 2008, New Yok. Proceeedings [...]. New York: 2008, p. 1-16.

NUNES, L. L. S. T.; ROSA, L. Q.; SOUZA, M. V.; SPANHOL, F. J. Educação em Rede: tendências tecnológicas e pedagógicas na sociedade em rede. EmRede, Porto Alegre, v. 3, n. $2,2016$.

OLIVEIRA, M. M. Como fazer pesquisa qualitativa. Petrópolis: Vozes, 2007. 
PAPERT, S. Mindstorms: children, computers and powerful ideas. New York: Basic Books, 1980.

PAPERT, S. The children's machine: rethinking school in the age of the computer. New York: BasicBooks, 1993.

PONTE, J. P. Novas tecnologias na aula de Matemática. Educação e Matemática, Lisboa, n. 34, p. 2-17, 1995.

PRADO, M. E. B. B. (Re)visitando o construcionismo para a formação do professor reflexivo. In: CONGRESSO RIBIE, 4., 1998, Brasília. Anais [...]. Brasília: 1998. p. 1-12.

SAMPAIO, P. A. S. R.; COUTINHO, C. M. G. F. P. Integração do TPACK no processo de ensino/aprendizagem da Matemática. Paideia, Santos, v. 6, n. 10, jul. 2014.

SCUCUGLIA, R. Narrativas Multimodais: a imagem dos matemáticos em performances matemáticas digitais. Bolema, Rio Claro (SP), v. 28, n. 49, p. 950-973, ago. 2014.

SORJ, B.; GUEDES, L. E. Exclusão digital: Problemas conceituais, evidências empíricas e políticas públicas. Novos estudos, São Paulo, n. 72, p. 101-117, jul. 2005.

SORJ, B.; REMOLD, J. Exclusão digital e educação no Brasil: dentro e fora da escola. Boletim Técnico do Senac, Rio de Janeiro, v.31, n. 3, p.6-17, set/dez. 2005.

TEDESCO, J. C. O compromisso docente com a justiça social e o conhecimento In: SILVA JUNIOR, C. A.; GATTI, B. A.; MIZUKAMI, M. G. N; PAGOTTO, M. D. S.; SPAZZIANI, M. L. (org.). Por uma revolução no campo de formação de professores. São Paulo: Editora Unesp, 2015. p. 119-131.

VALENTE, J. A. Informática na Educação no Brasil: análise e contextualização histórica. In: Valente, J. A. (org.). O Computador na sociedade do conhecimento. Campinas: Unicamp/Nied, 1999. p. 11-30.

VITAL, C. Performance Matemática Digital e GeoGebra: possibilidade Artístico Tecnológica em Educação Matemática. 2018. Dissertação (Mestrado em Educação Matemática) - Universidade Estadual Paulista, Rio Claro, 2018.

ZIMMERMANN, W.; CUNNINGHAM, S. Editors' Introduction: What is Mathematical Visualization? In: ZIMMERMANN, W.; CUNNINGHAM, S. (ed.). Visualization in Teaching and Learning Mathematics. Washington: The Mathematics Association of America, 1991. p. 1-7. 